\title{
Hop bitter acids inhibit tumorigenicity of hepatocellular carcinoma cells in vitro
}

\author{
MICHAEL SAUGSPIER ${ }^{1}$, CHRISTOPH DORN $^{1}$, BARBARA CZECH $^{1}$, \\ MANFRED GEHRIG $^{2}$, JÖRG HEILMANN ${ }^{3}$ and CLAUS HELLERBRAND ${ }^{1}$
}

\footnotetext{
${ }^{1}$ Department of Internal Medicine I, University Hospital Regensburg, Regensburg; ${ }^{2} \mathrm{Nateco}_{2} \mathrm{GmbH} \&$ Co. KG, Wolnzach; ${ }^{3}$ Department of Pharmaceutical Biology, Institute of Pharmacy, University of Regensburg, Regensburg, Germany
}

Received May 3, 2012; Accepted May 28, 2012

DOI: $10.3892 /$ or.2012.1925

\begin{abstract}
Bitter acids (BAs) from the hop plant Humulus lupulus L. exhibit multiple beneficial biological properties with promising effects in cancer therapy and prevention, but information regarding the effects on hepatocellular carcinoma (HCC) is missing. Here, we used two different hop bitter acid extracts enriched for either $\alpha$-acids or $\beta$-acids to obtain insight into whether biological activity varies between these two groups of BAs. At a concentration of $25 \mu \mathrm{g} / \mathrm{ml}$, only the $\beta$-acid rich started to induce aspartate transaminase (AST) release, and a significant increase was detected with $50 \mu \mathrm{g} / \mathrm{ml}$ of both extracts. Already at lower concentrations both extracts led to a dose-dependent inhibition of proliferation, and migration was suppressed at a concentration as low as $5 \mu \mathrm{g} / \mathrm{ml}$ in HCC cells. The focus on different signaling pathways revealed an inhibition of ERK1/2 phosphorylation, downregulation of AP-1 activity and an alleviation of nuclear factor $\kappa \mathrm{B}(\mathrm{NF} \kappa \mathrm{B})$ activity in HepG2 cells incubated with $5 \mu \mathrm{g} / \mathrm{ml}$ of both extracts, whereby the $\beta$-acid rich extract showed more pronounced effects. In conclusion, we identified ERK1/2, AP-1 and NFKB, which are important factors in tumor development and progression, as targets of hop BAs. Thus, these data suggest the potential use of BAs as functional nutrients for both prevention and treatment of HCC.
\end{abstract}

\section{Introduction}

Bitter acids (BA), which can be found in the female inflorescences of the hop plant Humulus lupulus L. in high amounts, are traditionally used for beer brewing as natural preserving agent and to add its typical bitterness and flavor (1). BA consist of two structurally related series, $\alpha$-acids (or humulones) and $\beta$-acids

Correspondence to: Dr Claus Hellerbrand, Department of Internal Medicine I, University Hospital Regensburg, D-93042 Regensburg, Germany

E-mail: claus.hellerbrand@klinik.uni-regensburg.de

Key words: Humulus lupulus L., hop, bitter acids, hepatocellular carcinoma, AP-1, nuclear factor $\kappa \mathrm{B}, \mathrm{ERK} 1 / 2$ (or lupulones), which are both characterized as prenylated acylphloroglucinols. Both groups are mainly composed of three analogues, and the main structural difference is that $\alpha$-BA are substituted with one isoprenyl side chain at C- 6 whereas $\beta$-BA contain two isoprenyl side chains at this position (Fig. 1). Recent studies have shown that both $\alpha$ - and $\beta$-BA exhibit various potent biological properties with promising effects for cancer therapy and prevention. BA induce apoptosis in fast-growing tumor cells in vitro and inhibit chemical induced tumor promotion in vivo (2-6). However, so far no studies are available, which assessed the effects of BA in hepatocellular carcinoma (HCC).

$\mathrm{HCC}$ is the fifth most frequent cancer worldwide (7). In most cases, patients have a background of chronic liver disease leading to liver cirrhosis, which is the main risk factor for the development of HCC $(8,9)$. HCC represents the cancer with the third highest mortality (10), and up until now, surgical resection or transplantation are the most promising treatment options of HCC. However, there is a high rate of disease recurrence since most patients are diagnosed at an advanced stage (8). Thus, small molecules which are able to target angiogenesis, apoptosis and specific signal transduction pathways have gained attention in cancer therapy (11).

The aim of this study was to assess the effect of BA on HCC cells in vitro. We used hop extracts enriched with $\alpha$ - or $\beta$-BA, respectively, to obtain first insight into whether biological effects vary between these two groups of BA.

\section{Materials and methods}

Cell isolation and cell culture. HCC cell lines HepG2 (ATCC HB-8065), PLC (ATCC CRL-8024), and Hep3B (ATCC HB-8064) were maintained in high glucose DMEM supplemented with penicillin $(400 \mathrm{U} / \mathrm{ml})$, streptomycin $(50 \mu \mathrm{g} / \mathrm{ml})$, L-glutamine $(300 \mu \mathrm{g} / \mathrm{ml})$ and $10 \%$ fetal calf serum (FCS; Sigma, Deisenhofen, Germany) and passaged at a 1:5 ratio every 3 days. Generation of conditioned medium (CM) from activated hepatic stellate cells was done as described (12).

Chemicals. Supercritical carbon dioxide hop extracts were provided by $\mathrm{Nateco}_{2}$ (Wolnzach, Germany). $\alpha$-rich extract ( $\alpha$-extract) contained 57.2\% $\alpha$-acids (humulone, cohumulone and adhumulone) and $18.3 \% \beta$-acids (lupulone, colupulone and adlupulone), whereas $\beta$-rich extract ( $\beta$-extract) contained $13.0 \%$ 
$\alpha$-acids (humulone, cohumulone and adhumulone) and $51.9 \%$ $\beta$-acids (lupulone, colupulone and adlupulone) as revealed by HPLC analysis (data not shown). Stock solutions of the BA containing extracts $(100 \mathrm{mg} / \mathrm{ml})$ were prepared by dissolving the extracts in DMSO. After a centrifugation step, unsolved compounds were removed, and the obtained stock solutions were aliquoted and stored at $-20^{\circ} \mathrm{C}$ prior to use. Samples indicated as controls were treated with an according concentration of DMSO. Final concentration of DMSO did not exceed $0.1 \%$ in all experiments. To ensure that the bitter acids and not concomitant substances are responsible for the observed activity, the BA from the $\beta$-extract were further purified. Therefore, the extract was solved in hexane and the obtained solution was transferred to a separating funnel and liquid-liquid extraction was done with sodium hydroxide ( $\mathrm{pH}$ 12.0). The sodium hydroxide solution (containing deprotonated BA) was acidified with hydrochloric acid (37\%) followed by liquid-liquid extraction with petroleum ether as second phase. Subsequently, purified BA as well as the fraction containing remnant lipophilic compounds (not soluble at $\mathrm{pH}$ 12.0) were dried using a rotary evaporator.

Separation into purified BA and remnant lipophilic compounds was checked by thin layer chromatography using silica gel plates (Merck, Darmstadt, Germany) and a solvent mixture of cyclohexane, ethyl acetate and glacial acetic acid (ratio 70:29:1). For visualization of purification success anisaldehyde spray reagent was used as described (13) (data not shown). Both fractions (purified BA and remnant lipophilic compounds) were pharmacologically tested in a proliferation assay.

Proliferation assay. Quantification of cell proliferation was measured applying colorimetric XTT assay (Roche Diagnostics, Mannheim, Germany) as described (12).

Migration assay. Migratory capacity of HCC cells was quantified using Cultrex 96 Well Cell Migration assay (Trevigen, Gaithersburg, USA) as described (14).

Quantification of ERK1/2 and NFKB activity. Phospho-p44/42 and phospho-p65 were quantified applying PathScan phosphosandwich ELISA (Cell Signalling Technology, Beverly, USA) as described (14).

AP-1 reporter gene assay. For transfections, HCC cells $\left(2 \times 10^{5}\right.$ cells per well) were seeded in 6-well plates and transfected with $0.5 \mu \mathrm{g}$ pAP-1 luc plasmid (Stratagene, La Jolla, USA) using Lipofectamine Plus reagent (Invitrogen, Karlsruhe, Germany) according to the manufacturer's instructions. For normalization of transfection efficiency, cells were contransfected with $0.2 \mu \mathrm{g}$ of pRL-TK plasmid resulting in a renilla luciferase acitivity (Promega, Mannheim, Germany). After 24 h, transfectionmedium was removed and cells were stimulated with the two hop extracts for $20 \mathrm{~h}$. Subsequently, cells were lysed and the luciferase activities were measured using a luminometric assay (Promega).

Statistical analysis. Values are presented as mean \pm SEM. Comparison between groups was made using the Student's unpaired t-test. A p $<0.05$ was considered statistically significant. All calculations were performed using the statistical computer

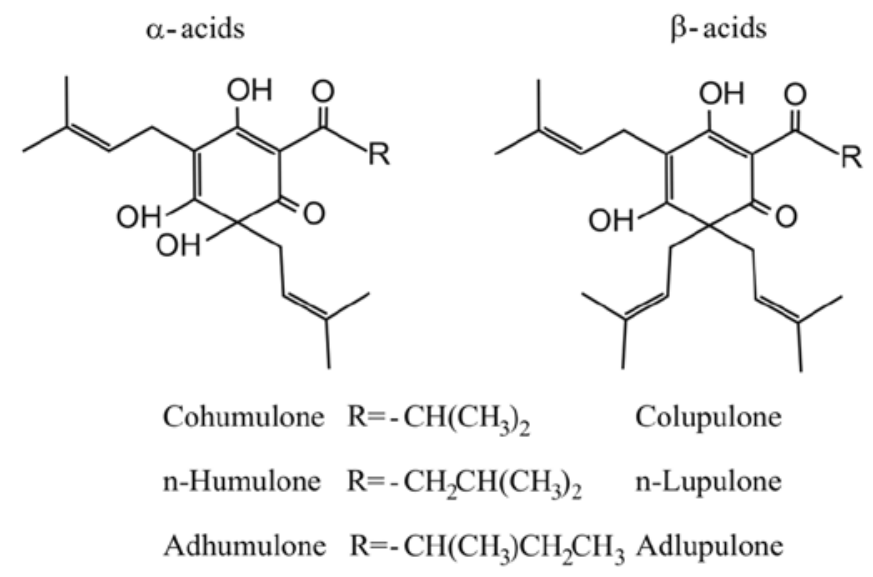

Figure 1. Chemical structure of hop bitter acids.

package GraphPad Prism version 4.00 for Windows (GraphPad Software, San Diego, CA, USA).

\section{Results}

Bitter acids induce cell death of HCC cells. Our first aim was to define the effective dose range of BA on different human HCC cell lines. Cells were incubated with indicated concentrations of an $\alpha$-rich extract ( $\alpha$-extract) and a $\beta$-rich extract ( $\beta$-extract) for $24 \mathrm{~h}$. Here and in subsequent experiments, control cells were treated with an equivalent amount of the solvent DMSO. Microscopic analysis revealed no alterations in BA treated HepG2 (Fig. 2A), Hep3B (Fig. 2B) and PLC cells (Fig. 2C) up to a concentration of $10 \mu \mathrm{g} / \mathrm{ml}$. Higher concentrations led to first morphological changes, and a concentration of $50 \mu \mathrm{g} / \mathrm{ml}$ caused cell bubbling in all three HCC cell lines. In line with these data, aspartate transaminase (AST) concentration in the supernatant of HepG2 cells treated with the two hop extracts did only slightly differ from control cells up to a concentration of $25 \mu \mathrm{g} /$ $\mathrm{ml}$, while AST levels were markedly increased upon incubation with concentrations of $50 \mu \mathrm{g} / \mathrm{ml}$ indicating cell injury (Fig. 2D and $\mathrm{E})$. Interestingly, $\beta$-extract showed more pronounced effects than $\alpha$-extract regarding morphological changes and induction of AST release. Similar results were obtained for Hep3B and PLC cells (data not shown).

Bitter acids reduce proliferation and block the migratory potential of HCC cells. Acquisition of a highly proliferative and invasive phenotype is a main characteristic of tumor cells. We therefore investigated the effect of the two hop extracts on cell cycle synchronized HCC cells. Incubation for $24 \mathrm{~h}$ with $15 \mu \mathrm{g} / \mathrm{ml} \beta$-extract led to a significant inhibition of the proliferation rate (Fig. $3 \mathrm{~B}$ ) whereas a concentration of $25 \mu \mathrm{g} / \mathrm{ml} \alpha$-extract was required to achieve an anti-proliferative effect on HCC cells (Fig. 3A). Next, we analyzed the effect of the hop extracts on the migratory capacity of HCC cells. Here, we applied a low concentration of BA-extracts $(5 \mu \mathrm{g} / \mathrm{ml})$ to exclude interfering effects on cell viability and proliferation, respectively. At this concentration both $\alpha$ - and $\beta$-extract exhibited a similar inhibitory effect on HCC cell migration (Fig. 3C). 
A
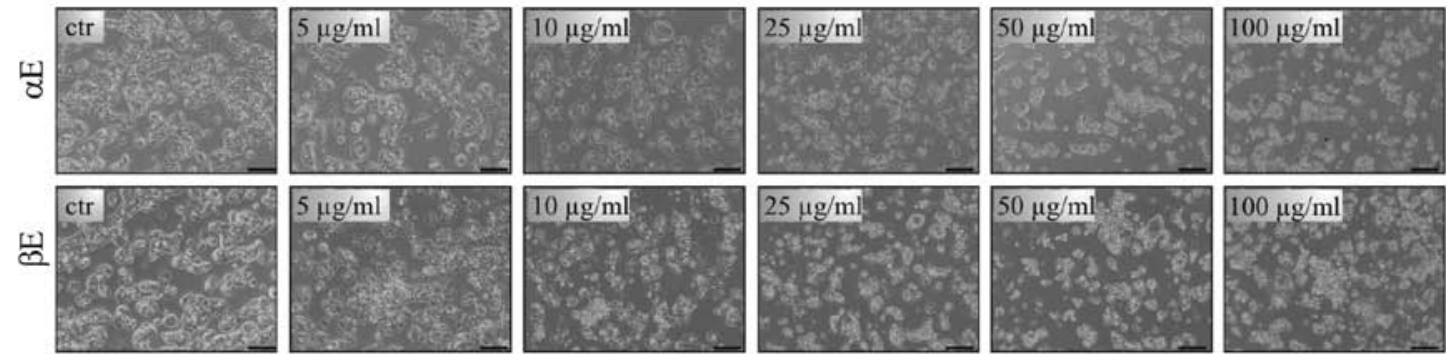

B
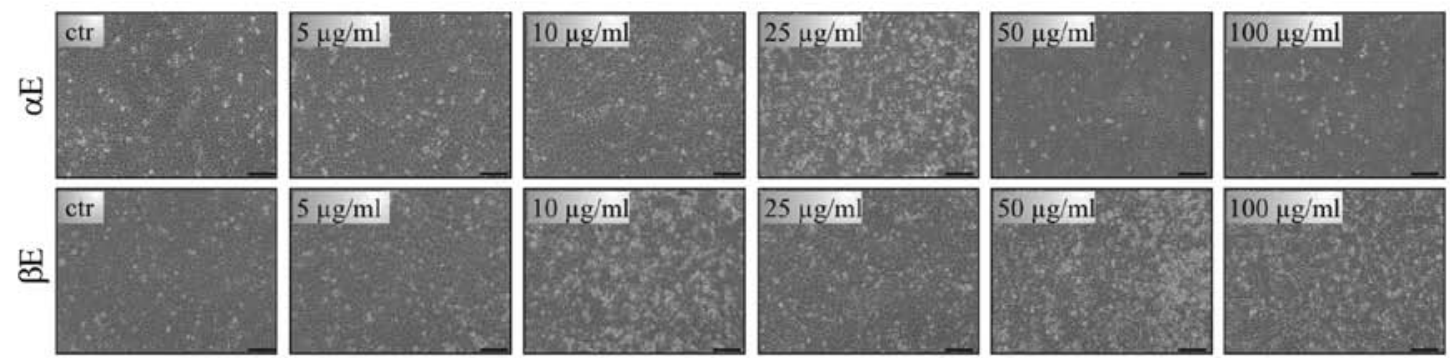

\section{C}
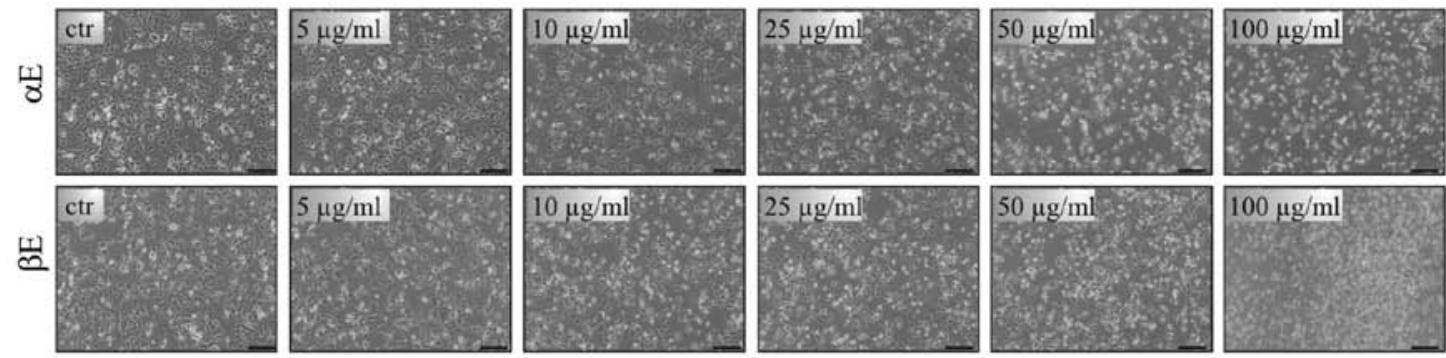

D

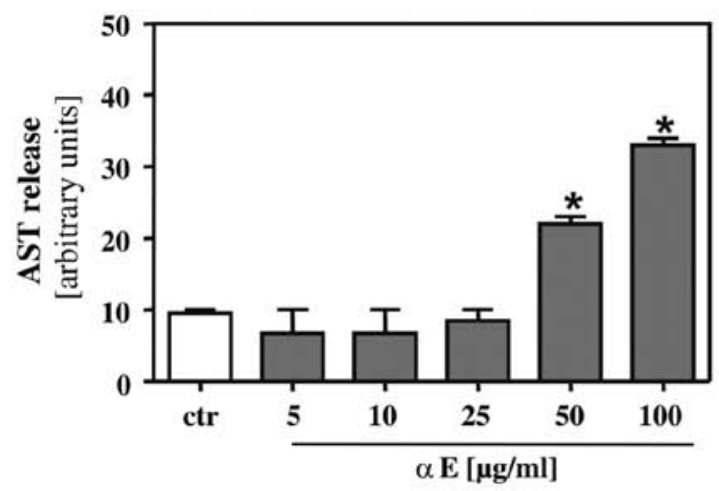

$\mathbf{E}$

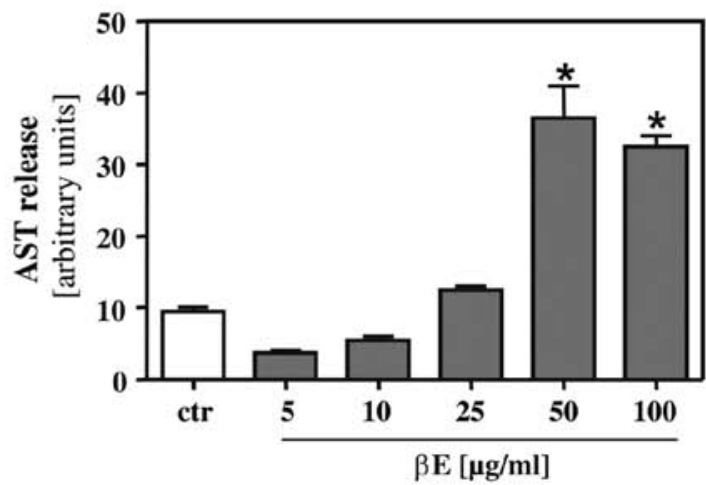

Figure 2. Bitter acids induce cell death of HCC cell lines in vitro. Three different human HCC cell lines were stimulated with indicated concentrations of an $\alpha$-rich $(\alpha \mathrm{E})$ and a $\beta$-rich ( $\beta \mathrm{E}$ ) hop extract. Representative phase-contrast images of (A) HepG2, (B) Hep3B and (C) PLC cells after 24-h incubation with the indicated concentrations of BA. Bars represent $200 \mu \mathrm{m}$. After 24-h stimulation, the amount of aspartate transaminase (AST) in the supernatants of HepG2 cells treated with (D) $\alpha \mathrm{E}$ and (E) $\beta E$ was measured as biomarker for cell injury. " $\mathrm{p}<0.05$ compared to control.

Bitter acids inhibit ERK1/2, $A P-1$ and $N F \kappa B$ activity in $H C C$ cells. To get insight into the molecular mechanism by which BA affect proliferation and migration of HCC cells, we analyzed different pathways, which are known to affect HCC progression. Extracellular signal-regulated kinase (ERK1/2) is often deregulated in $\mathrm{HCC}$, and its induction correlates with poor prognosis of HCC patients (15-17). Stimulation with $5 \mu \mathrm{g} / \mathrm{ml}$ of both hop extracts significantly reduced the amount of phosphorylated ERK1/2 in HepG2 cells (Fig. 4A). Interestingly, the inhibitory effect of $\beta$-extract was more potent compared to $\alpha$-extract. Once activated, ERK1/2 pathway induces different transcription factors including the activator protein-1 (AP-1) (15). Therefore, we next applied a reporter gene assay to assess AP-1 activity in HepG2 cells stimulated with the two hop extracts. Both of 
A

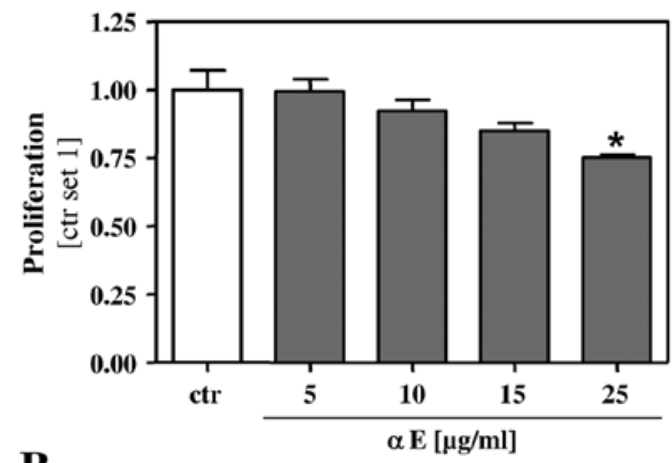

B

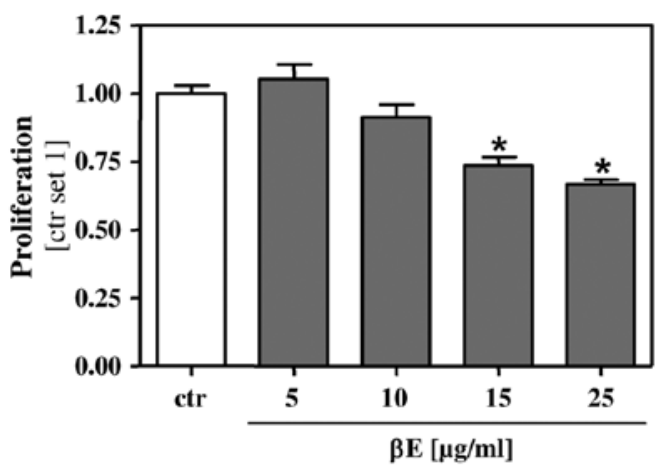

C

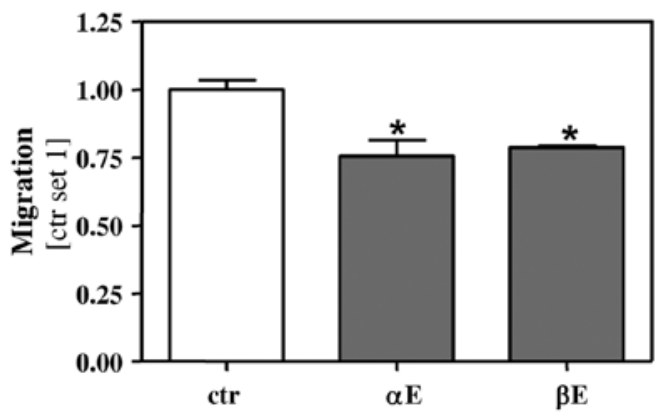

Figure 3. Bitter acids reduce proliferation and block the invasive potential of $\mathrm{HCC}$ cells in vitro. Proliferation of HepG2 cells treated with indicated concentration of $\alpha$-rich $(\alpha \mathrm{E})(\mathrm{A})$ and $\beta$-rich $(\beta \mathrm{E})(\mathrm{B})$ hop extracts applying the colorimetric XTT assay. (C) Quantification of the migratory capacity of HepG2 cells incubated with $5 \mu \mathrm{g} / \mathrm{ml} \alpha \mathrm{E}$ or $\beta \mathrm{E}$ compared to untreated control cells. * $\mathrm{p}<0.05$ compared to control.

them markedly inhibited AP-1 activity in HepG2 cells (Fig. 4B). Moreover, ERK-activation can also directly affect the transcription factor NFKB $(18,19)$, and we and others have shown that NFKB plays an important role in HCC progression $(12,20,21)$. We therefore investigated the influence of BA on $\mathrm{NF} \kappa \mathrm{B}$ activity. Both hop extracts significantly attenuated basal NFאB activity at a concentration of $5 \mu \mathrm{g} / \mathrm{ml}$. We further assessed the effect of both hop extracts on induced $\mathrm{NF} \kappa \mathrm{B}$ activity. To induce $\mathrm{NF} \kappa \mathrm{B}$ activation, HepG2 cells were stimulated with conditioned medium from activated hepatic stellate cells (HSC). Activated HSC which are regarded as the major profibrogenic cell type in the liver, secrete a variety of proinflammatory cytokines, and previously, we identified their influence on tumor aggressiveness (12). Importantly both hop extracts significantly alleviated
HSC induced $\mathrm{NF \kappa B}$ activity at concentrations as low as $5 \mu \mathrm{g} / \mathrm{ml}$ (Fig. 4C).

Bitter acids but not remnant lipophilic compounds of hop extracts affect proliferation of HCC cells. Finally, we analyzed whether concominant compounds present in the $\alpha$ - and $\beta$-extracts contribute to the observed anti-tumorous effects on HCC cells. We separated BA from the $\beta$-extract by liquidliquid extraction, and HepG2 cells were stimulated with the obtained purified bitter acids (pBA) and the remnant lipophilic compounds (rLC) at equimolar concentrations. Importantly, treatment with $\mathrm{pBA}$ revealed the same anti-proliferative effect as the original $\beta$-extract (Fig. 5A) whereas treatment with the remnant lipophilic compounds alone had no influence on proliferation (Fig. 5B). These findings confirmed that BA, but not remnant hop compounds in the extracts account for the observed effects on HCC cells.

\section{Discussion}

The aim of the present study was to analyze the effects of bitter acids (BA) on tumorigenicity of HCC cells. To obtain first insight into differential effects of $\alpha$-BA and $\beta$-BA we used hop extracts enriched with either one of these two related series and found that both extracts exhibited a profound effect on ERK1/2 as well as on AP-1 and NFKB activation. These signaling pathways are known to be pathophysiologically relevant in HCC cells $(12,15,16,18,20,21)$, and in line with this, both extracts also revealed inhibitory effects on proliferation and migration of HCC cells in vitro. Importantly, we could exclude that the observed effects derived from remnant lipophilic compounds in hop extracts. However, individual anti-tumorigenic effects were stronger upon stimulation with $\beta$-extract compared to $\alpha$-extract-mediated effects. One might speculate that the additional isoprenyl side chain of $\beta$-BA, which contributes to a higher lipophilicity and increased steric hindrance, may positively influence their effects on HCC cells. However, Cattor et al demonstrated a rapid and effective uptake of $\alpha$-BA into colon cancer cells in vitro (22). Furthermore, and notwithstanding the slight differences between $\alpha$ - and $\beta$-BA regarding anti-tumorigenic effects on $\mathrm{HCC}$, it has to be noted that $\alpha-\mathrm{BA}$ are the most abundant type of BA in beer whereas $\beta$-BA are only present in trace amounts (23). Still, different methods (i.e., using liquid supercritical carbon dioxide) were developed to isolate BA from hop cones in large quantities, and thus, independent of beer intake extracts enriched for either $\alpha$ - or $\beta$-BA may be potentially used as hepatoprotective dietary supplement.

Scarce information is available on the bioavailability of BA in vivo, and comprehensive data comparing $\alpha$-BA and $\beta$-BA are missing. After a single oral uptake of $940 \mathrm{mg}$ of isomerized $\alpha$-BA (called META060) Desai and colleagues detected serum concentrations of $4-15 \mu \mathrm{g} / \mathrm{ml}$ in men (24), which is within the dose range in which $\mathrm{BA}$ exhibit anti-tumorigenic effects on HCC cells in the present study.

With regards to the safety profile of BA, Farber et al did not detect any toxic effects on liver, kidney, bone marrow or myocardium in man after oral application of BA at a dose of $5.0 \mathrm{~g}$ per day for 3 months (25). Still, it has to be considered that HCC mainly develops in cirrhotic livers (7), which are 
A

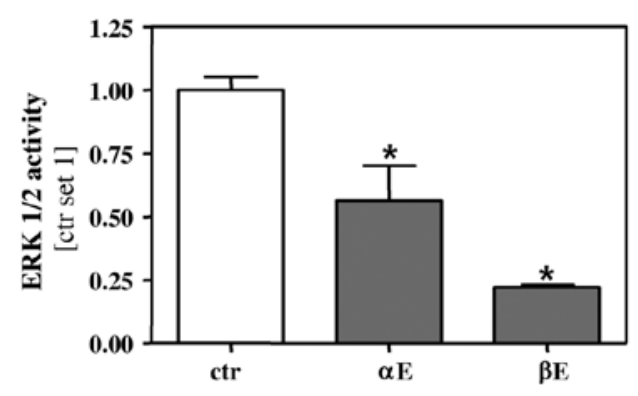

B

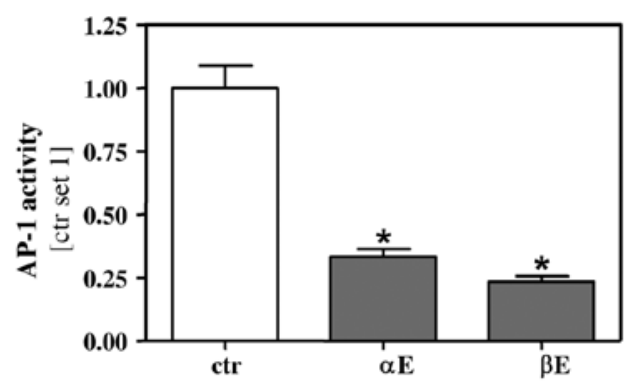

C

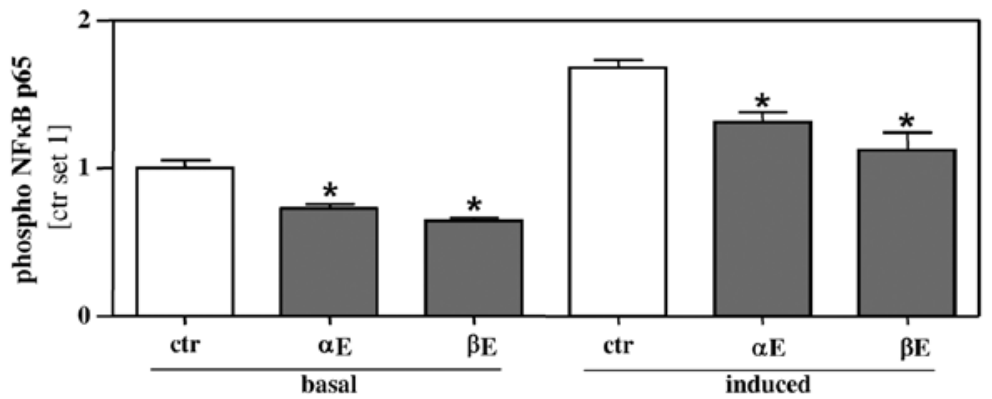

Figure 4. Bitter acids inhibit ERK1/2, AP-1 and NFאB activity of HCC cells in vitro. Effect of an $\alpha$-rich $(\alpha \mathrm{E})$ and a $\beta$-rich $(\beta \mathrm{E})$ hop extract (5 $\mu \mathrm{g} / \mathrm{ml})$ on different signaling pathways in HepG2. (A) Quantification of phospho-ERK1/2 after 24-h stimulation applying the ELISA technique. (B) AP-1 activity was measured after

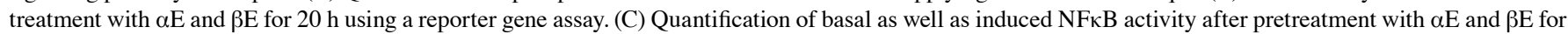
16 h. ${ }^{*}$ p $<0.05$ compared to control.

A

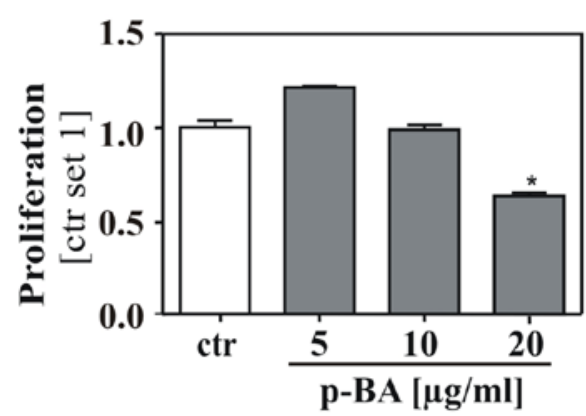

B

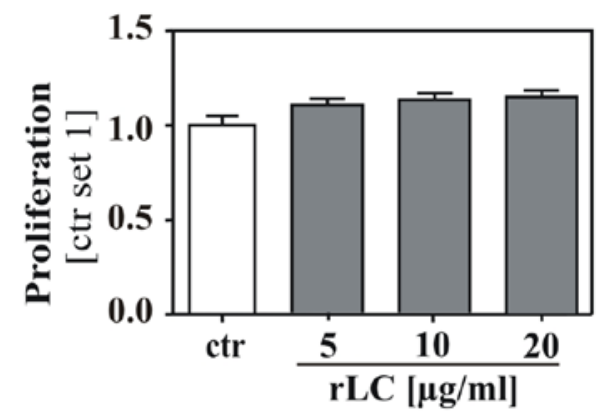

Figure 5. Remnant lipophilic compounds did not affect proliferation of HCC cells in vitro. Effect of purified bitter acids (A) and remnant lipophilic compounds of the original $\beta$ bitter acid extract (B) on the proliferation of HepG2 applying the colorimetric XTT assay. ${ }^{*}$ p $<0.05$ compared to control.

characterized by an impaired metabolic and detoxifying capacity. Therefore, special caution has to be taken in patients with chronic liver disease, and further studies in experimental fibrosis and HCC models are required. Still, the present study indicates the potential of BA as functional nutrient for both prevention and treatment of HCC.

\section{Acknowledgements}

We would like to thank Marina Fink and Ruth Schewior (Department of Internal Medicine I, University Hospital Regensburg) for excellent technical assistance. Further, this study was supported in part by an unrestricted research grant from the Joh. Barth \& Sohn GmbH (Nuremberg, Germany). Financial relationships of the authors with Joh. Barth \& Sohn GmbH are as follows: C.H. is a consultant, and M.S., C.D. and B.C. are working in the laboratory of C.H. M.G. is an employee of $\mathrm{NateCO}_{2}$.

\section{References}

1. Van Cleemput, Cattoor K, De Bosscher K, Haegeman G, De Keukeleire D and Heyerick A: Hop (Humulus lupulus)-derived bitter acids as multipotent bioactive compounds. J Nat Prod 72: 1220-1230, 2009 
2. Chen WJ and Lin JK: Mechanisms of cancer chemoprevention by hop bitter acids (beer aroma) through induction of apoptosis mediated by Fas and caspase cascades. J Agric Food Chem 52: 55-64, 2004

3. Lamy V, Roussi S, Chaabi M, Gosse F, Schall N, Lobstein A and Raul F: Chemopreventive effects of lupulone, a hop \{beta\}-acid, on human colon cancer-derived metastatic SW620 cells and in a rat model of colon carcinogenesis. Carcinogenesis 28: 1575-1581, 2007.

4. Lamy V, Roussi S, Chaabi M, Gosse F, Lobstein A and Raul F: Lupulone, a hop bitter acid, activates different death pathways involving apoptotic TRAIL-receptors, in human colon tumor cells and in their derived metastatic cells. Apoptosis 13: 1232-1242, 2008.

5. Tobe H, Kubota M, Yamaguchi M, Kocha T and Aoyagi T: Apoptosis to HL-60 by humulone. Biosci Biotechnol Biochem 61: 1027-1029, 1997.

6. Yasukawa K, Takeuchi M and Takido M: Humulon, a bitter in the hop, inhibits tumor promotion by 12-O-tetradecanoylphorbol-13acetate in two-stage carcinogenesis in mouse skin. Oncology 52 156-158, 1995.

7. Kirchner G, Kirovski G, Hebestreit A, Scholmerich J, Schlitt HJ, Stoeltzing $\mathrm{O}$ and Hellerbrand $\mathrm{C}$ : Epidemiology and survival of patients with hepatocellular carcinoma in Southern Germany. Int J Clin Exp Med 3: 169-179, 2010.

8. Bruix J, Boix L, Sala M and Llovet JM: Focus on hepatocellular carcinoma. Cancer Cell 5: 215-219, 2004.

9. Farazi PA and DePinho RA: Hepatocellular carcinoma pathogenesis: from genes to environment. Nat Rev Cancer 6: 674-687, 2006.

10. Parkin DM, Bray F, Ferlay J and Pisani P: Estimating the world cancer burden: Globocan 2000. Int J Cancer 94: 153-156, 2001.

11. Freise C, Ruehl M, Erben U, et al: A hepatoprotective Lindera obtusiloba extract suppresses growth and attenuates insulin like growth factor-1 receptor signaling and NF-kappaB activity in human liver cancer cell lines. BMC Complement Altern Med 11: 39, 2011.

12. Amann T, Bataille F, Spruss T, et al: Activated hepatic stellate cells promote tumorigenicity of hepatocellular carcinoma. Cancer Sci 100: 646-653, 2009.

13. Saugspier M, Dorn C, Thasler WE, Gehrig M, Heilmann J and Hellerbrand C: Hop bitter acids exhibit anti-fibrogenic effects on hepatic stellate cells in vitro. Exp Mol Pathol 92: 222-228, 2012.
14. Dorn C, Weiss TS, Heilmann J and Hellerbrand C: Xanthohumol, a prenylated chalcone derived from hops, inhibits proliferation, migration and interleukin-8 expression of hepatocellular carcinoma cells. Int J Oncol 36: 435-441, 2010.

15. Ito Y, Sasaki Y, Horimoto M, et al: Activation of mitogen-activated protein kinases/extracellular signal-regulated kinases in human hepatocellular carcinoma. Hepatology 27: 951-958, 1998.

16. Schmitz KJ, Wohlschlaeger J, Lang $\mathrm{H}$, et al: Activation of the ERK and AKT signalling pathway predicts poor prognosis in hepatocellular carcinoma and ERK activation in cancer tissue is associated with hepatitis C virus infection. J Hepatol 48: 83-90, 2008.

17. Tsuboi Y, Ichida T, Sugitani S, et al: Overexpression of extracellular signal-regulated protein kinase and its correlation with proliferation in human hepatocellular carcinoma. Liver Int 24: 432-436, 2004.

18. Nakano H, Shindo M, Sakon S, Nishinaka S, Mihara M, Yagita H and Okumura K: Differential regulation of IkappaB kinase alpha and beta by two upstream kinases, NF-kappaB-inducing kinase and mitogen-activated protein kinase/ERK kinase kinase-1. Proc Natl Acad Sci USA 95: 3537-3542, 1998.

19. Zhao Q and Lee FS: Mitogen-activated protein kinase/ERK kinase kinases 2 and 3 activate nuclear factor-kappaB through IkappaB kinase-alpha and IkappaB kinase-beta. J Biol Chem 274: 8355-8358, 1999.

20. Arsura M and Cavin LG: Nuclear factor-kappaB and liver carcinogenesis. Cancer Lett 229: 157-169, 2005.

21. Pikarsky E, Porat RM, Stein I, et al: NF-kappaB functions as a tumour promoter in inflammation-associated cancer. Nature 431: 461-466, 2004.

22. Cattoor K, Bracke M, Deforce D, De KD and Heyerick A: Transport of hop bitter acids across intestinal Caco-2 cell monolayers. J Agric Food Chem 58: 4132-4140, 2010.

23. Foster BC, Kearns N, Arnason JT, Saleem A, Ogrodowczyk C and Desjardins S: Comparative study of hop-containing products on human cytochrome p450-mediated metabolism. J Agric Food Chem 57: 5100-5105, 2009.

24. Desai A, Konda VR, Darland G, et al: META060 inhibits multiple kinases in the NF-kappaB pathway and suppresses LPS-mediated inflammation in vitro and ex vivo. Inflamm Res 58: 229-234, 2009.

25. Farber SM, Masten JM, Anderson HH, Gentry RW and Chin YC: Tolerance and effects of lupulon in man. Dis Chest 18: 10-15, 1950. 